\title{
Keteguhan Lentur dan Keteguhan Patah Sambungan Finger Joint Kayu Meranti (Shorea $S p)$ pada Posisi Sambungan Vertikal \& Horizontal
}

\author{
Iskandar \\ Prodi Rekayasa Kayu Politeknik \\ Pertanian Negeri Samarinda \\ iskandar.smd.799@gmail.com
}

\author{
Joko Priyono \\ Prodi Rekayasa Kayu Politeknik \\ Pertanian Negri Samarinda \\ jokopoltanesa@gmail.com
}

\author{
Yusdiansyah \\ Prodi Rekayasa Kayu Politeknik \\ Pertanian Negeri Samarinda \\ buyungagro@gmail.com
}

\begin{abstract}
Abstrak--Keterbatasan panjang kayu yang tersedia dilapangan mengharuskan bahan elemen sruktur disambung. Namun semakin panjang bahan elemen struktur tersebut, gaya lentur yang akan terjadi akan semakin besar bahkan dapat mengakibatkan patah bila beban yang bekerja pada bahan tersebut tidak seimbang dengan kemampuan dari pada bahan tersebut. Untuk itu perlu diteliti jenis sambungan yang bisa menahan gaya lentur dengan lebih baik. Proses pengujian penelitian ini menggunakan kayu solid dan papan finger joint yang dipotong dengan ukuran $2 \mathrm{~cm} \mathrm{x}$ $5 \mathrm{~cm} \mathrm{x} 20 \mathrm{~cm}$ masing masing sebanyak 15 pengulangan setiap pengujian. Pengujian yang dilakukan antara lain pengujian kadar air, pengujian kerapatan, pengujian MoE dan yang terakhir yaitu pengujian MoR.Dari hasil pengujian MoR dan MoE papan finger joint, didapat bahwa nilai MoE finger joint meningkat $31,75 \%$ terhadap nilai MoE kayu utuh, sedangkan untuk MoR finger joint telah menurun sebesar 24,14\% terhadap MoE kayu utuhnya.
\end{abstract}

Kata kunci: kayu solid, papan finger joint, keteguhan lentur, keteguhan patah

\section{Pendahuluan}

Kebutuhan manusia terhadap kayu sebagai bahan bangunan dewasa ini semakin meningkat, kayu-kayu komersil selalu menjadi komoditas yang penting bagi industri besar dan kecil. Namun dalam kondisi sekarang ini kayu yang bermutu tinggi serta berkualitas sangat sulit diperoleh, berdasarkan hal itu maka dirasa perlu dilakukan penelitian dengan memanfaatkan bagian kayu yang tidak terpakai atau limbah sebagai papan sambung. Kayu sering dipergunakan sebagai rangka kuda-kuda, gording, kosen pintu dan jendala, dan lain sebagainya. Gording merupakan bagian dari rangka atap yang melintang di atas rangka kuda-kuda yang satu ke rangka kuda-kuda yang lain. Gording memiliki bentang yang panjang dan tentu saja rangkaian balok ini bukan merupakan rangkaian balok yang utuh. Tetapi merupakan rangkaian dari beberapa balok kayu.
Hal ini disebabkan karena kayu yang tersedia dipasaran terbatas panjangnya. Keterbatasan panjang kayu yang tersedia di lapangan mengharuskan bahan elemen sruktur disambung. Namun semakin panjang bahan elemen struktur tersebut, gaya lentur yang akan terjadi akan semakin besar bahkan dapat mengakibatkan patah bila beban yang bekerja pada bahan tersebut tidak seimbang dengan kemampuan dari pada bahan tersebut. Untuk itu perlu diteliti jenis sambungan yang bisa menahan gaya lentur dengan lebih baik.

Penyambungan akan menghasilkan satu komponen struktural yang sesuai dengan kebutuhan sehingga akan didapatkan ukuran kayu yang sesuai dengan perencanaan sebelumnya. Akan tetapi, sambungan merupakan titik terlemah dalam suatu komponen struktur. Struktur banyak mengalami keruntuhan akibat gagalnya sambungan yang ada.

Oleh sebab itu dalam pelaksanaanya, pemilihan jenis sambungan dan pemasangan sambungan yang tepat sangat berdampak besar pada kekuatan struktur tersebut. Untuk menjadi sambungan yang baik, kayu memerlukan bahan lain yang berfungsi sebagai pengikat, Polivinil Asetat (PVAc) atau juga bisa disebut lem putih yang digunakan sebagai lem kayu digunakan sebagai pengikat untuk bahan-bahan berpori khususnya kayu. PVAc mempunyai banyak kelebihan diantaranya mudah didapat, serba guna, dan peka terhadap tekanan. Penelitian ini bertujuan membuat sambungan kayu yang bisa menangggung gaya lentur dengan lebih baik. Sehingga memenuhi syarat sebagai bahan elemen struktur yang berkekuatan tinggi. Dengan demikian penerapan jenis sambungan yang tepat bila pada balok kayu tersebut bekerja gaya lentur dan menambah pengetahuan tentang jenis sambungan kayu yang masih belum terlalu banyak diketahui.

Hasil yang diharapkan dari penelitian ini adalah untuk memperoleh informasi tentang pengaruh posisi sambungan vertikal terhadap keteguhan lentur dan keteguhan patah finger joint dari kayu meranti. 


\section{STUDI PUSTAKA}

\section{Keteguhan Lentur}

Modulus elastisitas merupakan pengukuran kemampuan kayu untuk menahan perubahan bentuk atau lentur yang terjadi sampai dengan batas elastisnya. Semakin besar bebannya, semakin tinggi tegangan yang timbul dan semakin besar perubahan bentuk yang terjadi sampai batas elastis. Modulus elastis kayu dapat dihitung melalui pemberian beban sebagai tegangan yang diberikan pada kayu dan mengamati penunjukan oleh garis rambut sebagai regangan. Penentuan mutu kayu pada umumnya diklasifikasikan menurut jenis kayu tersebut. Namun, parameter SNI (Standar Nasional Indonesia) modulus elastisitas dipakai untuk menentukan mutu kayu, bukan terhadap jenisnya tapi pada setiap balok dan potongan kayu tersebut (DapasPandeleke, 2017).

Kekuatan lentur atau Modulus of Elasticity (MoE) adalah suatu nilai yang konstan dan merupakan perbandingan antara tegangan dan regangan dibawah batas proporsi. Tegangan didefinisikan sebagai distribusi gaya per unit luas, sedangkan renggangan adalah perubahan panjang per unit panjang bahan. Modulus elastisitas (MoE) berkaitan dengan regangan, defleksi dan perubahan bentuk yang terjadi. Besarnya defleksi dipengaruhi oleh besar dan lokasi pembebanan, panjang dan ukuran balok serta MoE kayu itu sendiri. Makin tinggi MOE akan semakin kurang defleksi balok atau gelagar dengan ukuran tertentu pada beban tertentu dan semakin tahan terhadap perubahan bentuk (Haygreen dan Bowyer, 1993).

Menurut Sastradimadja (1997) dalam Yusdiansyah (2000), kayu dapat diberikan beban atau gaya mencapai batas maksimum akan terjadi perubahan dimensi tetapi apabila beban atau gaya tersebut dilepas maka kayu akan kembali pada keadaan semula.

\section{Keteguhan Patah}

Keteguhan patah adalah keadaan dimana gaya yang diberikan pada suatu benda diperbesar sampai mencapai batas maksimum, maka akan terjadi perubahan dimensi pada kayu tersebut, artinya bahwa apabila beban atau gaya tersebut dilepas maka kayu tidak akan kembali pada keadaan semula dan bila diteruskan akan terjadi kepatahan atau Modulus of Rupture (MoR) (Sastradimadja dalam Yusdiansyah (2000)).

Modulus of Rupture (MoR) dihitung dari beban maksimum (beban pada saat patah) dalam uji keteguhan lentur dengan menggunakan pengujian yang sama untruk MoE (Haygreen dan Bowyer, 1993).

Tegangan yang di hitung dari beban maksimum (beban pada saat patah) di sebut tegangan patah. Modulus patah (MOR) merupakan sifat mekanis kayu yang berhubungan dengan kekuatan kayu yaitu ukuran kemampuan kayu untuk menahan beban atau gaya yang bekerja padanya maksimal dan cenderung merubah bentuk dan ukuran kayu tersebut dengan kata lain kekuatan lentur patah merupakan sifat kekuatan kayu dalam menentukan beban yang dapat di pukul oleh suatu balok atau gelegar. (Kollman dan Cote, 1968).

\section{Sambungan Jari (Finger Joint)}

Sambungan merupakan bagian yang paling lemah, sehingga banyak kegagalan atau kerusakan struktur yang disebabkan oleh gagalnya sambungan. Oleh karena itu teknik penyambungan sangat berperan untuk mendapatkan struktur yang baik. Teknik penyambungan adalah teknik penggabungan bahan yang mempunyai bentang pendek dan terbatas sehingga menjadi bahan yang berbentang panjang. Teknik ini digunakan untuk membentuk dimensi bahan bangunan yang diperlukan sebagai bahan konstruksi. Ada beberapa jenis sambungan balok kayu yang dapat digunakan antara lain : sambungan tegak (butt joint), sambungan miring (scarf joint), sambungan jari (finger joint) (Awaludin dkk., 2005).

Sambungan jari yang umum digunakan dipabrikasi untuk panjang L (length) adalah $15 \mathrm{~mm} \mathrm{~s} / \mathrm{d}$ $20 \mathrm{~mm}$ (Castro dan Paganini, 1997). Sedangkan menurut Mohammad (2004), dalam Meng Gong (2009), di Amerika Utara sambungan jari untuk komponen struktural yang umum digunakan dengan panjang jari length yaitu antara $22 \mathrm{~mm}$ dan $29 \mathrm{~mm}$.

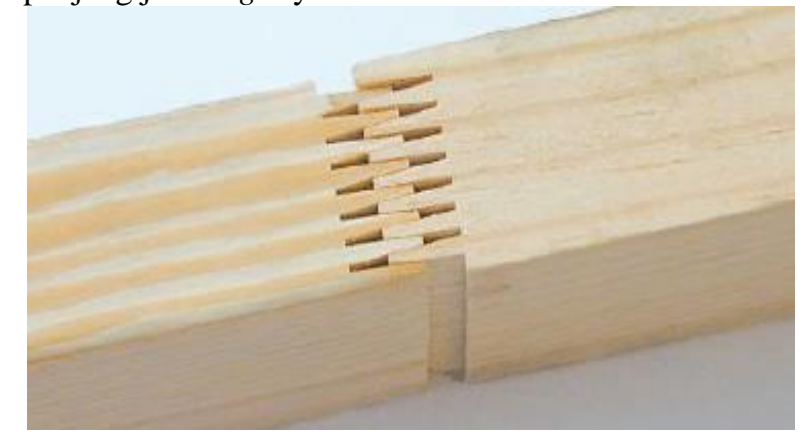

Sambungan Jari (Finger Joint)

\section{Meranti (Shorea sp)}

Meranti (Shorea spp.) adalah komoditas penting yang merupakan salah satu jenis tanaman komersil penghasil kayu utama di Indonesia. Marga shorea atau yang secara umum disebut kelompok meranti merupakan salah satu marga dari suku dipterocarpaceae yang tumbuh di dataran rendah. Dalam dunia perdagangan, kelompok meranti dibagi menjadi empat kelompok besar yaitu : kelompok Meranti Merah, kelompok Meranti Kuning, kelompok Meranti Putih, dan

kelompok balau (Wahyu dkk., 2020). Klasifikasi tumbuhan meranti adalah sebagai perikut :

$\begin{array}{ll}\text { Kerajaan } & \text { : Plantae } \\ \text { Divisi } & : \text { Magnoliophyta } \\ \text { Kelas } & \text { : Magnoliopsida } \\ \text { Ordo } & \text { : Malvales } \\ \text { Famili } & \text { : Dipterocarpaceae }\end{array}$


Genus : Shorea, Dipterocarpus, Vatica,Cotylelobium, Anisoptera, Dryobalanops, Hopea

\section{METODOLOGI}

Penelitian ini dilaksanakan selama \pm 3 bulan pada tahun 2021 yang terdiri dari persiapan penelitian, persiapan bahan baku, pelaksanaan penelitian dan analisis data.

\section{Bahan dan Alat}

Bahan

Bahan yang digunakan adalah papan finger joint dan papan solid yang didapatkan dari PT Oceanias Timber Products yang berlokasi di Jalan Ekonomi, Desa Loa Buah, Kota Samarinda

Alat
a. Meteran
b. Sircular Saw
c. Kaliper
d. Timbangan Digital
e. Desikator
f. Oven
g. Gegep
h. UTM (Universal Testing Mechine)

\section{Prosedur Penelitian}

1. Pembuatan contoh uji finger joint dilaksanakan di Laboratorium Rekayasa Pengolahan Kayu (Lab RPK) Program Studi Pengolahan Hasil Hutan, Jurusan Teknologi Pertanian.
a. Pemotongan Papan Finger Joint $2 \mathrm{~cm} \times 2 \mathrm{~cm}$ $x 30 \mathrm{~cm}$
b. Pemotongan Papan Solid $2 \mathrm{~cm}$ x $2 \mathrm{~cm}$ x 30 $\mathrm{cm}$

2. Standar pengujian Papan Solid dan Papan Finger Joint menggunakan SNI 01-7255-2006.

\section{Pengujian Sifat Fisis dan Mekanis}

Pengujian Kadar Air, Kerapatan, Keteguhan Lentur dan Keteguhan Patah dilakukan di Laboratorium Sifat Kayu dan Analisis Produk (Lab SKAP) Program Studi Pengolahan Hasil Hutan, Jurusan Teknologi Hasil Hutan.

1. Kadar Air (KA)

Pengukuran kadar air dilakukan dengan menimbang masing-masing contoh uji untuk mendapatkan berat kering udara (BKU), Kemudian Memasukan kedalam oven dengan suhu $103 \pm 2{ }^{\circ} \mathrm{C}$ selama 24 jam. Nilai kadar air dihitung dengan rumus:

$$
K A=\frac{B A-B K T}{B K T} \times 100 \%
$$

Keterangan:

$$
\begin{aligned}
& \mathrm{KA}=\text { Kadar Air }(\%) \\
& \mathrm{BA}=\text { Berat Awal }(\mathrm{g}) \\
& \mathrm{BKT}=\text { Berat Kering Tanur }(\mathrm{g})
\end{aligned}
$$

3. Kerapatan $\left(\mathrm{gr} / \mathrm{cm}^{3}\right)$

Pengukuran kerapatan papan solid dan papan finger joint berdasarkan bobot dan volume kering udara dengan ukuran $2 \mathrm{~cm}$ x $5 \mathrm{~cm}$ x $20 \mathrm{~cm}$. Nilai kerapatan papan solid dan papan finger joint dihitung dengan menggunakan rumus :

$$
\rho=\frac{M}{V}
$$

\section{Keterangan:}

$\rho \quad=$ Kerapatan $\left(\mathrm{g} / \mathrm{cm}^{3}\right)$

$\mathrm{M} \quad=$ Bobot contoh uji $(\mathrm{g})$

$\mathrm{V} \quad=$ Volume contoh uji $\left(\mathrm{cm}^{3}\right)$

4. Keteguhan Patah (MoR)

Pengujian keteguhan patah dilakukan sebanyak 15 kali ulangan dan dihitung dengan rumus:

$$
M O R=\frac{3 \cdot F_{\text {max }} \cdot L}{2 \cdot b \cdot h^{2}}\left(\frac{\mathrm{kg}}{\mathrm{cm}^{2}}\right)
$$

Keterangan:

$$
\begin{array}{ll}
\mathrm{F}_{\max } & =\text { Beban maksimum }(\mathrm{kg}) \\
\mathrm{L} & =\text { Jarak sangga }(\mathrm{cm}) \\
\mathrm{b} & =\text { Lebar contoh uji }(\mathrm{cm}) \\
\mathrm{h} & =\text { Tebal contoh uji }(\mathrm{cm})
\end{array}
$$

5. Keteguhan Lentur (MoE)

Pengujian keteguhan patah dilakukan sebanyak 15 kali ulangan dan dihitung dengan rumus:

$$
M O E=\frac{L^{3} \cdot \Delta F}{4 \cdot h^{3} \cdot b \cdot \Delta f}\left(\frac{k g}{\mathrm{~cm}^{2}}\right)
$$

Keterangan:

$$
\begin{array}{ll}
\Delta F & =\text { Selisih beban }(\mathrm{kg}) \\
\Delta f & =\text { Perubahan defleksi }(\mathrm{cm}) \\
\mathrm{L} & =\text { Jarak sangga }(\mathrm{cm}) \\
\mathrm{b} & =\text { Lebar contoh uji }(\mathrm{cm}) \\
\mathrm{h} & =\text { Tebal contoh uji }(\mathrm{cm})
\end{array}
$$

6. Pengolahan Data

Pengolahan data dilakukan dengan perhitungan nilai rata-rata menurut (Sudjana, 2013 : 109) menggunakan rumus sebagai berikut:

$$
\bar{x}=\frac{\sum x}{n}
$$

Keterangan:

$$
\begin{array}{ll}
\overline{\mathrm{x}} & =\text { Rata-rata } \\
\Sigma \mathrm{x} & =\text { Jumlah nilai } \\
\mathrm{n} & =\text { Banyaknya sampel }
\end{array}
$$

Nilai rata-rata selanjutnya digunakan untuk membandingkan antara kayu solid dan finger joint. 


\section{HASIL DAN PEMBAHASAN}

Dari hasil penelitian dan pengolahan data dari keteguhan lentur dan keteguhan patah bentuk sambungan papan finger joint dan kayu solid dari kayu meranti pada posisi sambungan vertikal pada sifat fisik meliputi kadar air dan kerapatan sedangkan pada sifat mekanik meliputi MoE ddiperoleh nilai rata-rata dari masing-masing pengujian yang daan MoR dapat dilihat pada tabel 1.

Tabel 1. Kelas Kuat Kayu Berdasarkan PKKI Tahun 1961

\begin{tabular}{|c|c|c|c|c|}
\hline $\begin{array}{c}\text { Kelas } \\
\text { Kuat } \\
\text { Kayu }\end{array}$ & Berat Jenis & $\begin{array}{c}\text { Tekan } / / \\
\text { Serat } \\
\left(\mathrm{kg} / \mathrm{cm}^{2}\right)\end{array}$ & $\begin{array}{c}\text { MOR } \\
\left(\mathrm{kg} / \mathrm{cm}^{2}\right)\end{array}$ & MOE $\left(\mathrm{kg} / \mathrm{cm}^{2}\right)$ \\
\hline I & $>90$ & $>650$ & $>1100$ & $>125.000$ \\
\hline II & $0,90-0,60$ & $650-425$ & $1100-725$ & $100.000-125.000$ \\
\hline III & $0,60-0,40$ & $425-300$ & $725-500$ & $80.000-100.000$ \\
\hline IV & $0,40-0,30$ & $300-215$ & $500-360$ & $60.000-80.000$ \\
\hline V & $<0,30$ & $<215$ & $<360$ & $<60.000$ \\
\hline
\end{tabular}

Untuk mengetahui data perhitungan masingmasing parameter adalah sebagai berikut:

\section{Pengukuran Kadar Air}

Dari hasil pengukuran nilai kadar air yang didapat adalah sebesar $12,57 \%$ untuk kayu utuh dan sebesar 12,33\% pada papan finger joint ratarata, perbedaannya tiak terlalu jauh, dimana kadar air kayu utuh sedikit lebih tinggi dibanding kadar air papan finger joint. Pada tabel 2. terbaca bahwa pengurangan kadar air pada papan finger joint hanya sekitar $1,95 \%$.

Tabel 2. Nilai Rata-rata Hasil Pengukuran dan Pengujian

\begin{tabular}{|c|l|l|l|l|l|l|}
\hline \multirow{2}{*}{ No } & \multirow{5}{*}{$\begin{array}{l}\text { Parameter } \\
\text { Pengujian }\end{array}$} & $\begin{array}{l}\text { Kayu } \\
\text { Utuh }\end{array}$ & $\begin{array}{l}\text { Finger } \\
\text { Joint } \\
\text { Horizon } \\
\text { tal }\end{array}$ & $\begin{array}{l}\text { Finger } \\
\text { Joint } \\
\text { Vertikal }\end{array}$ & $\begin{array}{l}\text { Finge } \\
r \\
\text { Joint } \\
\text { Rata- } \\
\text { rata }\end{array}$ & $\begin{array}{l}\text { Penin } \\
\text { g- } \\
\text { katan } \\
(\%)\end{array}$ \\
\hline 1 & $\begin{array}{l}\text { Kadar Air } \\
(\%)\end{array}$ & 12.57 & 12,38 & 12.28 & 12,33 & $-1,95$ \\
\hline 2 & $\begin{array}{l}\text { Kerapatan } \\
\left(\mathrm{g} / \mathrm{cm}^{3}\right)\end{array}$ & 0.52 & 0,52 & 0.52 & 0,52 & 0 \\
\hline 3 & $\begin{array}{l}\text { Keteguhan } \\
\text { Lentur } \\
(\text { MoE) } \\
\left(\mathrm{kg} / \mathrm{cm}^{2}\right)\end{array}$ & 67.30 & 113.761 & 63.597 & 88.67 & 31,75 \\
\hline 4 & $\begin{array}{l}\text { Keteguhan } \\
\text { Patah } \\
(\mathrm{MoR}) \\
\left(\mathrm{kg} / \mathrm{cm}^{2}\right)\end{array}$ & 601,3 & 552,56 & 416,34 & 484,4 & $-24,14$ \\
\hline
\end{tabular}

2. Kerapatan

Dari hasil pengukuran kerapatan sebanyak 15 kali pengulangan nilai rata-rata yang didapat dari kedua contoh uji adalah sebesar $0,52 \mathrm{~g} / \mathrm{cm}^{3}$. Hal tersebut dapat difahami bahwa karena volume perkat yang ada pada 1 sampel yang berukuran 2 $\mathrm{cm} \times 2 \mathrm{~cm} \times 2 \mathrm{~cm}$ sangat kecil sehingga berat perekat digunakan tidak berarti akibatnya kerapatannya sama seperti kayu utuhnya.
Secara teoritis, jika kayu cukup kering maka kerapatan tergantung dari banyaknya rongga udara (rongga sel) yang dapat diisi dengan bahan pengisi ke dalam dinding sel kayu, begitu juga jika menggunakan bahan perekat.

3. MoE (Modulus Elastisitas)

Dari hasil pengujian MoE sebanyak 15 kali pengulangan untuk masing masing contoh uji nilai rata-rata yang didapat adalah bahwa nilai $\mathrm{MoE}$ dari kayu utuh lebih kecil dibanding nillai MoE rata-rata dari papan finger joint. Nilai MoE kayu solid yaitu sebesar $67.308 \mathrm{~kg} / \mathrm{cm}^{2}$ dan nilai MoE papan finger joint rata-rata sebesar $88.679 \mathrm{~kg} / \mathrm{cm}^{2}$, dan jika dihitung telah terjadipeningkatan sebesar $31,75 \%$, hal membuktikan bahwa papan finger joint cukup dapat diandalkan penggunaannya untuk menghasilkan produk papan sambung yang kuat, pemilihan perekat dan metode sambungan yang digunakan juga harus tepat. Tingginya nilai MoE finger joint ini akibat daya dukung kekuatan rekat yang cukup handal dalam menahan tegangan tarik antar kayu yang direkatkan. Daya rekat suatu kayu bisa dipengaruhi oleh zat ekstraktif yang berada di dalam kayu, yang membuat perekat tidak bisa menempel dengan sempurna pada kayu yang direkat, jika hal ini terjadi maka sudah pasti nilai MoE finger joint akan lebih rendah dari kayu utuhnya. Peningkatan MoE finger joint rata-rata terhadap MoE kayu utuh adalah sebesar 31,75\% (Tabel 2).

\section{MoR (Modulus Patah)}

Dari hasil pengujian MoR sebanyak 15 kali pengulangan untuk masing masing contoh uji nilai rata-rata yang didapat adalah bahwa kayu utuh memiliki nilai MoR yang lebih tinggi daripada Nilai MoR finger joint rata-rata, yaitu 601,38 $\mathrm{kg} / \mathrm{cm}^{2}$, sedangkan nilai MoR finger joint rata-rata hanya sebesar $484,45 \mathrm{~kg} / \mathrm{cm}^{2}$. Penurunan nilai MoR disini mungkin karena kayu disini sebetulnya memang seolah-olah sudah memang patah yang sengaja disambung, sehingga kekuatan sambungan pastilah tidak sama dengan kayu seutuhnya. Penurunan nilai MoR finger joint rata-rata terhadap MoR kayu utuh adalah sebesar 24,14\% (Tabel 2).

\section{KESIMPULAN}

Dari pengujian Kadar Air, Kerapatan, MoE dan MoR kayu solid dan papan finger joint menghasilkan nilai kerapatan dan kadar air yang relatif sama tetapi berbeda untuk nilai MoE dan MoR. MoE papan finger joint rata-rata meningkat sebesar 31,75\% terhadap MoE kayu utuhnya, sedangkan pada MoR terjadi sebailknya dimana MoR papan finger joint ratarata menurun sebesar 24,14 \% terhadap MoR kayu utuhnya. Berdasarkan hasil pengujian MoE dan MoR, maka papan finger joint kayu meranti masuk kedalam 
kategori Kelas Kuat III, menurut tabel PKKI Tahun 1961.

\section{DAFTAR PUSTAKA}

Afifah, T 2018. Pemanfaatan Ampas Tebu (Saccarum officinarum) Untuk Pembuatan Papan Partikel. Program Studi Teknologi Hasil Hutan. Jurusan Teknologi Pertanian Politeknik Pertanian Negeri Samarinda.

Awaludin, A., Irawati, I.S., 2005. "Konstruksi Kayu“", Biro Penerbit Teknik Sipil Jurusan Teknik Sipil UGM, Yogyakarta

Castro, G., Paganini, F., 1997, Parameters Affecting End Finger Joint Performance In Polar Wood, International Conference of IUFRO S 5.02 Timber Engneering, Denmark.

Dapas S. O. dan Pandeleke R. 2017. Pengujian Kuat Lentur Kayu Profil Tersusun Bentuk Kotak. Jurnal Sipil Statik Vol.5 No.2.

Elvan Wahyu, Evi Sribudiani dan Tuti Arlita. 2020. Inventarisasi Permudaan Meranti (Shorea spp.) Pada Arboretum Kawasan Universitas Riau Kota Pekanbaru Provinsi Riau. Department of Forestry, Faculty of Agriculture, University of Riau Address Bina Widya, Pekanbaru, Riau.

Felix Yap, KH, 1964, KONSTRUKSI KAYU, Penerbit Bina Cipta, Bandung

Haygreen, J.G. dan Bowyer, J.L. 1993.. Hasil Hutan dan Ilmu Kayu Suatu Pengantar. Diterjemahkan oleh Hadikusumo, S.A. dan Prawirohotmodjo, S. Gajahmada University Press. Yogyakarta.

Hindrawan P. 2005. Pengujian Sifat Mekanis Panel Structural Dari Kombinasi Bamboo Tali (Gigantochloa apus Bl. ex. (Schult. F.) Kurz)[skripsi]. Bogor (ID): IPB

Kollman Dan Cote,1968 Pengujian Modulus Elasitas Kayu dengan Metode Two Point Loading Universitas Sumatra Utara

Prayitno, T.A., 1996. Perekatan Kayu. Bagian Penerbitan Yayasan Pembina Fakultas Kehutanan UGM. Yogyakarta.

Sudjana, Nana. 2013. Dasar-Dasar Proses Belajar Mengajar. Bandung: Sinar Baru Algesindo

Yusdiansyah, 2000. Studi Sifat Fisika dan Mekanika Papan Partikel dari Jenis Kayu Gmelina (Gmelina arborea), Kayu Makaranga (Macaranga gigantean). Jurusan Pengolahan Hasil Hutan. Politeknik Pertanian Negeri Samarinda. Samarinda 